\title{
Diş hekimliğinde preklinik ve klinik eğitim çeşitliliği
}

\author{
Funda Akaltan(0000-0001-6744-6312) ${ }^{\alpha}$ \\ Selcuk Dent J, Diş Hekimliği Eğitimini Yeniden Düşünmek - Özel Sayı
}

(Doi: 10.15311/selcukdentj.563351)

Başvuru Tarihi: 11 Mayıs 2019 Yayına Kabul Tarihi: 01 Ağustos 2019

\section{öz}

Diş hekimliğinde preklinik ve klinik eğitim çeşitliliği

Diş hekimliği eğitiminin esas amacl; öğrencilere klinik uygulamaları geliştirmek için yardımcı olmaktır. Klinik eğitim; diş hekimliği müfredatının dörtte üçünden fazlasını kapsar ve çoğunlukla dişlerin protetik veya restoratif işlemleri için gerekli olan psikomotor becerileri geliştirmeye yöneliktir. Öğrenciler; bir seri tanımlanmış beceriyi fakülte kliniklerinde eğitmenlerin gözetiminde, uygulama yaparak tecrübe ederler. Humanistik eğitim standartları için gereken simülasyon hasta olarak fantomların kullanıldığı preklinik eğitim; genellikle restoratif işlemlerle sınırıdır. Preklinik laboratuvarlarında yapılan bu eğitim; klinikte hastalarla iletişim, enfeksiyon kontrolü ve klinik uygulama aşamaları konusunda öğrencilerin tecrübe kazanmalarını sağlamada zayıf kalır. Bu derleme çalışmasında; sanal gerçeklik, bilgisayar destekli ve kendi kendine yapılan değerlendirmeler, standardize hastalar, toplum destekli klinik uygulamalar ve vaka tamamlama esasına dayanan klinik uygulamalar gibi güncel preklinik ve klinik eğitim modelleri tartışılarak, diş hekimliği öğrencilerinin becerilerinin iyileştirilmesine yönelik öneriler getirilmektedir.

\section{ANAHTAR KELIMELER}

Diş hekimliği eğitimi, yansıtıcı uygulama, standardize hastalar, sanal gerçeklik, toplum-destekli eğitim

\section{ABSTRACT}

Preclinical and clinical education variety for dentistry

Main objective of dental education is to help students to develop their clinical skills. The clinical training covering the three-quarters of overall dental curriculum focuses mainly on developing the psychomotor skills required for restorative and prosthetic procedures. Dental students exercise a serial of previously defined professional skills under the supervision in their faculty clinics. Preclinical training using manikins as a simulated patient neccessary for a humanistic education standards is usually limited to restorative procedures. Preclinical education held in laboratories do not usually support students to gain professional and interprofessional experiences related to patient relations, control of enfection and the steps of clinical procedures. In this review study, today's preclinical and clinical training models such as virtual reality, computer-based assesments, self-evaluating, standardized patients, community-based clinical training and case completion model are being discussed to be able to make some suggestions for improving skills of dental students.

\section{KEYWORDS}

Dental education, reflective practice, standardized patients, virtual reality, community-based education

Diş hekimliği günümüz müfredatı; geleneksel, entegre veya bunların karışımı şeklindeki felsefeyi uygulayarak, tasarım stili açısından farklııı göstermektedir. " "Geleneksel müfredat”; preklinik temel bilimler ile sonraki senelerde uygulamalı eğitimle birlikte klinik deneyim kazandıır. Dersleri esas alır ve önceden tanımlanmış, disipline dayalı eğitimde, konuların biraraya getirilerek anlaşımasını zorlaştıır. "Entegre müfredat"; alanlar ve konulara göre farklı disiplinleri bir araya getirir. ${ }^{2}$ Ders vermeye dayalı eğitim ve kendi kendine yönlendirilen öğrenme ve probleme dayalı veya vakaya dayalı öğrenimi esas alan küçük eğitim gruplarını kombine eder. Genellikle probleme dayalı eğitimde dersler çok azdır veya hiç ders yoktur; bunun yerine gerçek hayattan yola çıkan problem veya senaryolara dayanan, öğrenci-yönetimindeki küçük grup eğitimlerini cesaretlendirir. ${ }^{3}$ Diş hekimliği eğitiminde; öğrenci merkezli öğrenimi önemseyen, geleneksel müfredat formatlarından uzaklaşarak, daha entegre çıktılar ve yeterliğe dayalı modellerin önemini benimseyen öneriler yayınlanmaktadır. ${ }^{2,4-7}$

Diş hekimliği, diğer tıp fakültesi programları gibi müfredatın bilimsel yapısı nedeniyle daha çok teknik beceriler üzerinde yoğunlaşır. Ayrıca diş hekimliği eğitiminde; öğrenciler geri dönüşümü olmayan invaziv uygulamaları tecrübe ederler. ${ }^{8}$

\footnotetext{
${ }^{\alpha}$ Ankara Üniversitesi Diş Hekimliği Fakültesi, Protetik Diş Tedavisi Anabilim Dalı, Ankara
} 
Beceri; belirli bazı motor fonksiyonların veya araç gerecin belli bir düzeydeki ustalıkla belirli bazı görevleri yerine getirebilmek üzere kullanımasıdır. Beceri kavramı yeterlik ile birlikte ifade edilir. ${ }^{8}$

Yeterlik; belli şartlar altında bir becerinin belli standartlara uygun olarak yapılabilmesidir. Bilgi, beceri ve davranışların mesleğin bireysel yönlerine uygun olarak karışımıdır. ${ }^{8,9}$

Mezun diş hekimlerinin sadece klinik yeterlik kazanmakla kalmayıp, topluma hizmet sunabilmek için iyi uyum becerilerine (soft skills) sahip olmaları da gerekir. Bu beceriler 21. yüzyıl becerileri olarak da bilinir; iletişim, eleştirel düşünme ve problem çözme, takım çalışması gücü, yaşam boyu öğrenme ve bilgi yönetimi, girişimci, etik, ahlak ve profesyonellik ve liderlik becerileri olarak tanımlanır. ${ }^{10}$

Diş hekimliği eğitiminde laboratuvar ve klinik şartlar esas bileşenlerdir. Bu iki ortamın bir araya getirilmesi; öğrenmenin, düşünsel-kavramsal, duyusal-duygusal ve psikomotor-fiziksel olmak üzere farklı alanlarını biraraya getirmek ve uygulamak açısından önemlidir. ${ }^{11}$

\section{Preklinik Eğitim}

Geleneksel olarak hastalarda uygulama yapmadan önce, öğrenciler kavramların tanıtılığı preklinik teorik (didactic) derslere katıı ve daha sonra laboratuvarda çalışılar. Klinik eğitimin geliştirilebilmesi için preklinik laboratuvar ortamında hümanistik eğitim tekniğini kullanmak çok önemlidir; esas bileşeni ise anatomik model ve maketlerdir. ${ }^{11,12}$

Laboratuvar ortamında öğrenciler; tekrar yapma şansını elde ettikleri simülatöre monte edilen bir simülasyon kafa üzerinde uygulamaları gerçekleştirir; böylece psikomotor becerilerini geliştirerek, el becerilerini ve hünerlerini çabuklaştırılar. ${ }^{9}$

Eğitmen, anatomik modeller, eğitim slaytları, video filmleri kullanarak kazanılması gereken becerileri hasta ile olan ilişkileri defalarca tekrarlayarak göstermelidir. Öğrenciler, gözetim altında gerçek duruma benzer ortamda anatomik modeller üzerinde hem becerilerini hem de hasta ilişkileri ile ilgili uygulamalarını defalarca tekrarlayarak yapmalıdır. Öğrenciler, model üzerinde çalışmalarla beceri kazandıktan ve beceride yeterlik seviyesine geldikten sonra gerçek hasta ile çalışabilirler. ${ }^{13}$

Erişkin eğitiminde anatomik modeller ve maketlerin kullanımının birçok faydası vardır: ${ }^{13}$

- Öğrenmeyi kolaylaştııır.

- Beceri kazanılması ve yeterliliği arttırır.

- Beceri yeterliliğine ulaşmak için gerekli olan tekrar sayısını azaltır.

- Klinik beceri eğitiminin bir dershanede veya laboratuvarda ve klinik uygulamaların olmadığı bir zamanda yapılmasını sağlar.

- Vaka sayılarının az olduğu durumlar veya hastalıklar için de eğitim alınmasını sağlar.

- Temel eğitim için gerekli olan zamanı kısaltır ve böylece maliyeti azaltır.

- Hastaya zarar verebilecek hataları düzeltme olanağı verir.

- Hastanın maruz kalacağı riski minimuma indirir. 
Dental simülatörlerde uygulama yapmak; hastaya zarar vermeyi engelleyerek, kontrollü ve güvenli bir ortamda öğrencilerin başlıca becerilerine yardımcı olur. Bununla birlikte son model teknolojiyle donatılmış simülasyon laboratuvarları bile, öğrencilerin klinik ortamda geniş seçenekli tedavi tekniklerini uygulayarak hasta tedavi etmeleri için yeterli deneyim kazandıramazlar. ${ }^{14}$ Silikon lastik ve plastik diş gibi dental simülasyonda kullanılan materyaller çürük bir diş, çekilmiş veya kanamalı bir dişeti, diş fraktürü, oral mukoza patolojileri ve hatta mine ve dentinin fiziksel özelliklerini yansıtamaz. Fantom dişler; asitle pürüzlendirme veya adeziv uygulamaya uygun değildir; hatta çoğu ölçü malzemesi oda sıcaklığında değil, vücut sıcaklığında sertleşecek şekilde formüle edildiğinden, laboratuvar ortamında daha farklı sürede sertleşirler. Çürük mevcut olmayan dişleri prepare etmek gibi, öğrenciler genellikle tedavinin sadece ideal koşullarda yapıldığını zannederler. Fantom dişlerle ideal dizimde olan anatomik ark pozisyonlarında sabit ve hareketli bölümlü protez vakaları üzerinde çalışıllar. Preklinik simülasyon koşulları sadece ideal tedavi üzerinde odaklandığından, öğrenciler kliniğe girdikleri ilk senede hastalardaki farklılıklara odaklanır ve yeni ortama adapte olmak konusunda zorlanırlar. ${ }^{14}$

Bazı fakülteler preklinik programlarına gerçek hastalarla karşılaşmayı ilave ederler; bu uygulamalar preklinik fantom çalışmalarına ilave hasta senaryolarından, öğrencilerle interaktif olarak çalışabilen bilgisayar destekli programlara kadar değişiklik gösterir. ${ }^{15}$ Yöntemin ne olduğuna bakılmaksızın, bu tarz preklinik eğitimde amaç; davranışsal, biyomedikal ve klinik becerileri gerçek hastayla birleştirmektir. Gerçek hastalar; hasta görüşmesi uygulamalarıyla, öğrencilerin iletişim becerilerini değerlendirmede de kullanılır.

Üçüncü sınıf öğrencilerinin çürüğü radyografik olarak teşhis edebilme ile zihinlerinde beliren fikir ve düşünceleriyle ilgili anlama özelliklerini geliştirmesinde interaktif online bir programın etkisi bir pilot çalışmayla ${ }^{16}$ değerlendirilmiş; bu tür programların dersin etkinliği ve öğrencilerin beceri seviyelerini iyileştireceği ileri sürülmüştür.

Avrupadaki 25 farklı ülke ve 48 fakültedeki preklinik diş hekimliği becerilerinin müfredat içeriği, eğitim ve öğrenme stratejileri ile değerlendirme yöntemlerini incelemek amacıyla bir çalışma ${ }^{17}$ yapılmış ve bazı tespit ve öneriler oluşturulmuştur: (1) Avrupa'daki preklinik eğitimi açısından farklılıklar vardır. (2) Çekirdek klinik becerilerin hastaların doğrudan güvenliğini etkilediği düşünüldüğünde, Avrupa'da eğitim alan tüm öğrencilerin hasta tedavi etmeden önce bu konularda uygulama yapmaları konusunda daha fazla çaba sarf edilmelidir. (3) Preklinik becerilerin öğrenim çıktıları, eğitim aktivileri ve değerlendirmeleri işbirliği oluşturmak üzere paylaşılmalıdır. (4) Standardizasyon getirmek üzere lokal ve ülke çapında müdahaleler yapılmalıdır.

Avrupa'daki fakültelerde hasta tedavisinden önce verilen çekirdek preklinik beceri eğitiminde \% 95 ile en fazla yer alan konu; çapraz enfeksiyondur. İletişim becerileri (\% 69) ve takım çalışması (\% 58) bunu takip eder. Yansıtıcı uygulama; \% 48 ile en düşük kapsamdadır. ${ }^{17}$

Yansıtıcı uygulama (reflective practice); deneyimleyerek öğrenmeyi amaçlar; gerçek, komplike ve zor durumların çözümünde kullanılan uygulamalardır. ${ }^{18}$ Davranışda yansıma (reflection in/on action); bir olay veya aktivite hakkında düşünmek için bilinçli çaba sarfetmektir; konuyla ilgili neyin olumlu neyin zor olduğunu anlamamıza yardımcı olur ve gelecekte bu durumu iyileştirmek, geliştirmek veya farklı şekillerde yapmak için nasıl plan yapacağımızı gösterir. Hastalara yüksek kalitede ve güvenli tedavi planlamayı ve yapmayı kolaylaştııı. Uygulama sıralaması; bir şey yapmak - neyin iyi neyin kötü olduğunu düşünmek - gelecekteki uygulamalarımızda ne etkisi olduğunu düşünmek - yeni uygulamayı yerine getirmek - ....yeniden başlamak şeklindedir. "Olayın içinde yansıma" veya "sonrasında yansıma” şeklinde iki farklı uygulaması da mevcuttur. Aktivite gerçekleşirken yapılan yansıma uygulamasında; yeni 
bir şey yaparken veya sıra dışı bir uygulama yaparken, yansıma uygulaması gerçekleştirilir veya üzerinde düşünülür. Uygulama sonrasındaki yansımada ise olay tamamladıktan sonra, uygulama hakkında düşünülür ve bu bilgi deneyime dönüştürülür.

Klinik muayene ve çapraz enfeksiyon kontrolü en yüksek oranda (\% 73) değerlendirilen çekirdek preklinik beceriler olup; iletişim becerisi, takım çalışması, postür ve yansıtıcı uygulama; fakültelerin sadece yarısında ele alınmıştır. ${ }^{17}$ Tüm fakülteler hasta tedavisinden önce, anterior ve posterior aproksimal preparasyonlar, çürük yönetimi, kompozit restorasyonlar, okluzal preparasyonlar, pulpa perforasyonu, kök kanal tedavileri gibi operatif klinik becerileri değerlendirmektedir. Fakültelerin yarısından daha azı hasta tedavisine geçmeden önce veneer (\% 29) ve rezin tutuculu köprüleri (\% 31) değerlendirmektedir. Fakültelerin \%69'u ders boyunca ve sürekli olarak, \% 8'i dersin sonuna doğru ve yine \% $8^{\prime} i$ sadece bir defa değerlendirme yapmaktadır. ${ }^{17}$

Hasta tedavisine geçmeden önce çekirdek preklinik becerilerin öğreniminde klinik çalışma ortamıyla direkt ilişkili olan beceriler; çapraz enfeksiyon kontrolü, el yıkama, acil uygulamalarla başedebilme ve klinik ortamını hazırlama şeklinde sıralanmaktadır. ${ }^{17}$ Hasta tedavisiyle indirekt ilişkili olan beceriler ise iletişim ve takım çalışması olarak belirtilmiştir. Fakültelerin yarısından azında yansıtıcı uygulama eğitimi yapılmaktadır ve zorluklarından bahsedilmiştir. ${ }^{18} \mathrm{Her}$ fakültede ortak olan durum; değerlendirilen becerilerin öğretilenlerden daha az oluşudur; hatta 6 fakültede hiçbir çekirdek preklinik beceri değerlendirilmemektedir.

Geleneksel canlı demonstrasyon yapmak; laboratuvar tekniklerini öğretmede genelde kullanılan bir yöntem olmasına rağmen, özellikle öğrenci sayısının fazla olduğu durumlarda bazı sakıncaları da mevcuttur. Diş dizimi bilgi ve becerilerini öğrencilerin canlı demonstrasyon veya video seyrederek geliştirmesinin incelendiği bir araştırmada; ${ }^{19}$ video izleyen öğrencilerin tam protezler için diş dizimi yapma becerilerinde canlı demonstrasyon izleyenler kadar başarı sağladığı görülmüştür. Video seyreden öğrenci grubunda bilginin gelişmesi anlamında daha fazla başarı sağlanmıştır. İyi planlanmış ve açıklamalarla donatılmış videoların canlı demonstrasyonlar kadar faydalı olduğu görülmüştür. Daha iyi bir öğrenme ortamının sağlanması için, preklinik laboratuvarlarında video gösterimi esnasında öğrenciler ve eğitmenler arasında interaktif iletişimin sağlanması faydalı olacaktır. ${ }^{19}$

Simülasyon ve sanal gerçeklik simülasyon (virtual reality simulation) teknolojileri; görsel ve duyusal bilgilerin sunumunda online sürekli geri bildirim sunmak için bir fırsat yaratır. ${ }^{20}$ Diş hekimliği eğitmenleri simülasyonu esasen öğrencilerin gerçek hastaları tedavi etmeden önce motor becerilerini öğrenmeleri için güvenli bir eğitim ortamı oluşturmak üzere kullanmışlardır. Simülasyon aynı zamanda dental kliniğe geçişi kolaylaştırmak ve bir seri simüle hasta senaryosunun kullanımıyla öğrencilerin preklinik deneyimlerini iyileştirmek amacıyla da kullanılmıştır. ${ }^{21}$

Modern okullarda; hızlı gelişen bilimsel ve klinik bilgi temeli ile komplike dental tedavi yaklaşımları müfredatı daha da yoğunlaştırmaktadır. Bu durum müfredatın aşıı yüklenmesine ve öğrencilerin yansıma uygulamaları ve analiz çalışmalarına daha az zaman ayırarak, klinik becerilerini geliştirmelerine engel olmaktadır. ${ }^{1}$ Preklinik psikomotor beceri bileşenleri sanal gerçeklik uygulamaları ile ümit verici bir düzeye çekilmeye çalışılmaktadır. ${ }^{22,23}$

Motor becerilerin öğrenilmesinde geri bildirim, hareketin bir sonucu olarak mevcut tüm dokunsal bilgileri içerir. ${ }^{24}$ Geri bildirimi oluşturmanın birçok yolu vardır; içsel veya dışsal, tek veya çok yönlü ve devamlı veya kesintili olabilir. Geri bildirim performans neticesi hakkında bilgiyi (öğrenci uygulamanın tüm aşamaların tamamladıktan sonra eğitmen tarafından verilen puanlama-sonuç bilgisi) veya performansın kalitesi ve hareket özellikleri hakkında bilgiyi 
(geleneksel dental eğitim ortamında mevcut olmayan-performans bilgisi) içerebilir. ${ }^{25}$ Simülasyon uygulamaları sürecinde sonuç bilgisi şeklindeki geri bildirimin etkili motor beceri öğrenimini ortaya koyan en önemli faktörlerden biri olduğu bildirilmiştir. ${ }^{26,27}$

Diş hekimliğinde simülasyon eğitimi; öğrenci için güvenli uygulama yapma ve işlemsel becerilerini, hastalar üzerinde uygulama yapmadan önce belirlenen standartlara/yeterliklere ve öğrenim çıktılarına göre geliştirme imkanı bulmaları açısından önemli bir çekirdek müfredat bileşenidir. ${ }^{1}$ Klinik uygulama için gereken farklı tekniklerin öğrenimindeki simülasyon uygulamaları; geleneksel olarak doğal veya sentetik dişler içeren fantom kafalarda yapılır. Sanal gerçekliğin dental müfredat içindeki uygulamalarının artması; işlemleri tekrarlama ve standardize etme kolaylığı ile öğrencilerde doğrudan gözlem yapma ve malzeme sarfını azaltmak için tercih edilir. ${ }^{1}$

Sanal gerçekliğe dokunma duyusunun ilavesi; kullanıcıya duyusal bir geri bildirim kazandırarak, gerçekliği iyileştirmiştir. ${ }^{28}$ Ör; Diş preparasyonunda, kullanıcı dişin sertliğini fark ederek, dentini mineden ayırt edebilir. Dokunma duyusunun ilavesi; iş performansını arttırmakta, ${ }^{28,29}$ daha az teknik hatayla, daha hızlı ve hassas şekilde tamamlama imkanı vermekte ${ }^{30}$ ve öğrencinin klinik uygulamalara geçişini kolaylaştırmaktadır. ${ }^{31}$ Sanal gerçeklik simülasyon sistemleri periodontoloji, oral ve maksillofasiyal cerrahi ve operatif diş hekimliği alanlarında eğitim senaryoları üretmeye uygundur.

Sanal gerçeklik simülatörlerinin lisans uygulamalı diş hekimliği eğitiminde kullanımının objektif izlemeye dayalı değerlendirme üretmek ve beceri kazanma oranlarını iyileştirmede etkili olduğu gösterilmiştir. ${ }^{32}$ Buna ilaveten, düşük görsel kabiliyete sahip bireylerin simülasyon eğitiminde, geleneksel eğitime göre daha fazla yararlandığı görülmüştür. ${ }^{33}$ Fantom kafa simülatörleri ile yapılan geleneksel preklinik uygulama eğitiminde, eğitmenin sadece sonuç konusunda geri bildirim vermesi yerine, uygulama süreci boyunca devamlı ve anında geri bildirim yapmasının, öğrencinin performans gelişiminde önemli derecede gelişmeye sebep olduğu gösterilmiştir. ${ }^{25}$ Acemi öğrencilerin simülatörden tek tip (sadece görsel) geri bildirim almasının eğitim boyunca el beceri performanslarını geçici olarak iyileştirdiği; ancak bunun kalıcı olmadığı sonucuna varımıştır. ${ }^{34}$ Sanal gerçeklik simülasyonunun diş hekimliği eğitimine dahil edilmesi ve tecrübeli eğitmenlerin geri bildirimleri ile birlikte ele alınması; temel el becerisi eğitimini hızlandırabilir. ${ }^{21}$ Araştırmadaki öğrencilerin tümünde, daha düşük hata oranları ve daha az sürede iş bitirme ile sonuçlanan performans artışı görülmüştür.

lowa College of Dentistry and Dental Clinics; bilgisayar destekli öğrenim/bilgisayar destekli simülasyon sistemini müfredatına ve preklinik derslerine ilave ederek, yeni teknolojiyi eğitimde aktif hale getirmiş ve subjektif değerlendirmelere ilaveten objektif bir geri bildirim oluşturmuştur. ${ }^{35} \mathrm{Bu}$ yaklaşım; öğrencilerin altın standart olarak kabul edilen objektif kriterlerden sapmaları kendilerinin tespit etmelerine ve diş preparasyonlarının aşırı-az miktarda, andırkatıı veya aşııı eğimli olması durumunda oluşan renk haritalarını yorumlayabilmelerine imkan vermektedir. Diş preparasyonunun prensipleri ve kendi kendine değerlendirme (self-evaluating) becerileri geleneksel olarak fakültelerde Power Point sunumları, videolar, canlı demonstrasyonlar, kendi kendine değerlendirmeye yönelik kontrol listeleri ve eğitmenler tarafından yapılan görsel geri bildirimler ile öğretilir. ${ }^{36}$ Bilgisayar destekli öğrenimin; öğrenim sürecini iyileştirmeye yönelik ilave dijital bir boyut üreterek, bu geleneksel eğitimi tamamlaması gerekir. Yeni teknolojik yaklaşımdan beklenti; ilave dijital geri bildirimin öğrencilerin ideal diş preparasyonu üretecek parametreleri daha net ve daha doğru şekilde anlamalarını sağlamaktır. ${ }^{35}$ Bununla birlikte, 80 adet ikinci sınıf öğrencisi ile yapılan araştırmada ${ }^{35}$ dijital diş preparasyonu değerlendirme teknolojisinin kullanımı; öğrencilerin 
preparasyon tekniği ve kendi kendini değerlendirme becerilerini etkilememiş; eğitmenler tarafından yapılan görsel değerlendirme ve dijital değerlendirme skorları sadece iki kişide kısmen uyum sağlamıştır.

Teorik dersler ve dental laboratuvar uygulamaları tek başına preklinik öğrencilerinin şaşkına dönmesine ve dental uygulamaları anlamalarında zorluğa neden olmaktadır. ${ }^{37}$ Protez uygulamalarıı öğretmek için standardize hastaların kullanımı bu problemlerin çözümüne yardımcı olabilir. Herbir aşamayı hasta üzerinde gördüklerinde daha iyi anlarlar. Standardize hasta deneyimi Arizona College of Dental Medicine'ın müfredatında ikinci sınıf öğrencilerinin laboratuvar uygulamalarında kullanılmakta ve teorik dersler ve preklinik laboratuvar uygulamalarına ilaveten simüle edilmiş protez randevularında standardize hastaların kullanımı, öğrencilerin eğitim deneyimlerini iyileştirmektedir. ${ }^{37}$ Diş hekimliği eğitimlerinin ikinci senesinde standardize hastalarla buluşan öğrencilerin; dördüncü sınıfta gerçek hastalarla karşılaştıklarında, anahtar tedavi seçeneği bileşenlerini daha iyi kullanabildikleri görülmüştür. ${ }^{38}$

Standardize hastalar; sağlık mesleklerinin eğitiminde, gerçeğe uygun klinik görüşmeler ve muayene senaryoları için eğitilmiş olan aktörlerdir. ${ }^{39,40}$ Standardize hastaların kullanımı; öğrencilerin klinik becerileri öğrenebilmeleri ve uygulama yapabilmeleri, hem bu amaçla eğitilmiş olan hastalar hem de eğitmenlerden geri bildirim almak için güvenli ve kontrollü ortamların oluşturulmasına imkan sağlar. ${ }^{41}$

Standardize hastalar; diş hekimliği eğitiminde öğrencilerin geriatrik diş hekimliği açısından yetiştirilmesi ve değerlendirilmesi, tedavi planlamalarının sunumu, hastayla görüşme becerileri ve medikal acil uygulamalarda kullanılmaktadır. ${ }^{39} \mathrm{Bu}$ senaryolardaki ortak amaç; sadece belirli seviyelerde yetiştirilen diş hekimleri için klinik ve iletişim becerilerini geliştirmek ve değerlendirmektir. İletişim becerilerini içeren standardize hasta deneyimine sahip olan öğrencilerin; yeterliklerini korudukları ve kişilerarası becerilerini iyileştirdikleri bildirilmiştir. ${ }^{42}$

\section{Klinik Eğitim}

Klinik ortam; öğrencilerin sadece eleştirel düşünme, problem çözme ve daha sonraki kavramsal becerileri uygulama kapasiteleri değil, preklinikte öğrenilen kavramlar ve başlıca becerilerin hatılanması ve tanınmasının değerlendirilmesiyle, preklinik dersleri tamamlar ve güçlendirir. ${ }^{8}$

Klinik ortam; yeterli ve bağımsız klinik pratiği sergileyebilecek mezunların eğitimi için esastır. ${ }^{43}$ Diş hekimliği öğrencileri genelde çoktan seçmeli sınavlar, laboratuvar uygulamaları, günlük puanlamalar, klinik yeterlik sınavları ile değerlendirilirler. ${ }^{8}$ Klinik yeterlik; bilgi, deneyim, eleştirel düşünme ve problem çözme becerileri, profesyonellik, etik değerler ile teknik ve uygulama becerilerini içerir. ${ }^{43}$ Klinik ortamın kullanımı; öğrencilerin deneyim ve uygulama yapma hızlarını arttırmaları için uzun süre uygulama yapmalarına fırsat veren ve öğrencinin öğrenim çıktılarının değerlendirilmesi için değerli bir yöntemdir. ${ }^{8,44}$

Klinik eğitimde demonstrasyon videoları, animasyonlar ve kendi kendine öğreten alıştırmalar kullanılmasına rağmen; öğrencilerin, internet kaynakları ve bilgisayardan seyretmek yerine, fakülte eğitmenlerini seyrederek daha iyi öğrendikleri rapor edilmiştir. ${ }^{45}$

Graffam; ${ }^{46}$ klinik eğitmenler tarafından uygulanan öğretim yaklaşımını karşılayan uygun modellerin olmadığını bildirmiş; yeterli spesifik öğretme modelinin, klinik eğitmenlerin görevlerini yerine getirmeleri için rehber olabileceğini ileri sürmüştür. Kavramsal çıraklık eğitim modeli; "düşünmeyi yüzeye çıkararak, görünür hale getirmek" tir. Bu 
yaklaşım; öğrencilerin denetim altındayken klinik uygulamaları gözleme, uygulama ve başarmalarını kolaylaştırabilir. ${ }^{47}$

Öğrencilerin kavramsal ve kavramsal olmayan becerilerini elde etmeleri için planlanan 6 öğretim yöntemi: Model oluşturma (modelling), koçluk (coaching), yapı oluşturma (scaffolding), telafuz (articulation), yansıma (reflection) ve keşif (exploration) tir. ${ }^{47} \mathrm{Bu}$ model; klinik öğretimde geri bildirim, kendini değerlendirme ve fakülte gelişimi için kullanışı bir uygulama olarak önerilir; öğrencilerin bilgi ve klinik uygulama becerilerini nasıl biraraya getirdiklerini değerlendirir. ${ }^{48}$

Eğitim laboratuvarları olarak hizmet veren fakülte klinikleri; 21. yüzyıl model pratiğine uygun olarak düzenlenmemiştir. Licari ve Evans ${ }^{14}$ klinik eğitimde değişiklikler yapmada zorluk yaşadıklarını, aşıı yüklenmiş müfredatttan kurtulup, restoratif tedavilere odaklanamadıklarını bildirmişlerdir. Tek diş restorasyonları ve diş kayıpları klinik çalışma saatlerinin \% 66'sını, müfredatın ise \% 45'ini kapsamaktadır. Fakülteler müfredatlarına yeni teknolojiler, interprofesyonel eğitim/uygulama, kanıta-dayalı diş hekimliği ve eleştirel düşünme gibi konuları ilave etmede de zorluk yaşamaktadır. Rutkauskas ve ark.ları ${ }^{49}$ mezunların çocuklar ve özel ihtiyaçları olan hastaların tedavilerinde de bilgi ve beceri eksikleri olduğunu bildirmişlerdir. Mezunların \% 76'sı 6 yaş altındaki çocuk tedavisinde yetersiz olduklarını, \% 66'sı ise fakültelerinde bu alanda hiç eğitim almadıklarını ifade etmişlerdir.

Günümüzde fakültelerin çoğunda disipline dayalı eğitim uygulanır ${ }^{50}$ ve kapsamlı hasta tedavisi sağlanırken, klinik beceriler pratisyen hekimin intiyaçları doğrultusundadır (profilaksi, periodontal muayene, komplike olmayan diş çekimleri, tek kanal tedavileri ile hareketli ve sabit protezler); tedavi seansları eğitmenlerin gözetiminde tamamlanır. Fakültedeki eğitmenler; öğrencilerin tedavi seanslarının her birini, tedavi sonuna kadar gözlemler; ancak bu durum hastanın tedavi seanslarını ve tedavinin tamamlanma süresini uzatır. Diş hekimliği fakültelerindeki hastaların \% 42'sinin maliyet ve hastaya ulaşılamaması nedeniyle yarım kaldığı bildirilmiştir. ${ }^{51}$

Genelde diş hekimliği öğrencileri klinik eğitimlerini fakültelerinin yönetiminde olan kendi kliniklerinde tamamlarlar. Dental fakülte kliniklerinin esas hedefi öğrencileri eğitmektir; ancak deneyimli dental asistanlar ve destek görevlileri nedeniyle öğrencilerine seri tedavi oluşturmak için fırsat vermezler. ${ }^{52}$

Diş hekimliği fakülteleri öğrencilerinin mezun olduklarında intiyaçları olan klinik deneyimin büyük bir çoğunluğunu almaları için geniş kliniklere sahip olurlar. Birleşmiş Milletler'de 2010-2011'de dental kliniklerde toplam 2000 saatlik eğitim verilmektedir. Bu klinikler öğrencilerin, farklı derecelerde eğitmen yardımıyla, oldukça geniş alanda tedavinin neredeyse tamamını gerçekleştirmelerini sağlar. ${ }^{53} \mathrm{Bu}$ eğitim modelinde hastaların tedavileri yetersiz kalır ve devlet desteğine ihtiyaç duyar. Eğitmenler kontrol edici veya gözlemci olarak görev yapar ${ }^{54}$ ve bir klinik eğitim döneminde 6-8 öğrenciye eğitim verir. Tedaviyi esas olarak öğrencilerin yerine getirmesi ile komplike ve medikal problemleri olan hastaların ihtiyaçları tam olarak karşılanamaz.

Bazı diş hekimliği fakültelerinde, öğrencileri gözlemleyen eğitmenlerin aynı zamanda hastaları tedavi ettiği klinik eğitim modeli uygulanır. ${ }^{55}$ Toplum destekli klinikleri kullanmanın faydası klinik eğitimin daha ekonomik oluşudur. ${ }^{53}$ Toplum destekli kliniklerde eğitim alan öğrencilerin 4-5 kat daha fazla sayıda hasta tedavi edebildikleri ve mezun olduklarında daha verimli oldukları ifade edilmektedir.

Klinik eğitimde; öğrencinin bilgisi, becerisi ve kültürel yeterliklerini iyileştiren toplum destekli (community-based) öğrenme yaygınlaşmaktadır. ${ }^{56}$ Diş Hekimliği Akreditasyon Komisyonu (CODA- Commission on Dental Accreditation); 2-25 no'lu standardında, Amerika'daki fakültelerde "öğrencilerin hizmet ederken öğrenme tecrübesi 
(service-learning experience) ve/veya toplum destekli öğrenme deneyimi kazanmaları için fırsat yaratılması ve öğrencilerin bu konuda yüreklendirilmesi”ni; böylece görevlerinin kültürel bileşenine yardımcı olmak ve öğrencilerin topluma hizmet başarılarını arttırmalarını zorunlu kılar. ${ }^{57} \mathrm{Bu}$ gereksinimi yerine getirebilmek için; birçok fakülte toplum destekli eğitimi müfredatlarına almıştı; öğrenciler genelde dördüncü senelerinde dental kliniklerin dışında rotasyon görevi yaparlar. ${ }^{56}$

Yeterli hizmet veren kliniklerde toplum destekli eğitim alan öğrencilerin ödeme mekanizması, envanter (demirbaş, malzeme çizelgesi) kontrolü, üretim raporları gibi muayenehane yönetimi klinik becerilerinde daha başarılı oldukları kaydedilmiş; bu öğrenciler geleneksel eğitim alanlara göre daha yüksek vaka tamamlama başarısı elde edip, zamanında mezun olabilmişler; ${ }^{58}$ daha öz güvenli yetişmiş ${ }^{59-61}$ daha fazla hasta tedavi deneyimi kazanmışlardır. ${ }^{62}$ Öğrenciler; tedavileri esnasında zamanı daha etkili kullanabilmiş; ${ }^{59}$ teknik ve hastayı yönetme becerilerini iyileştirmişlerdir. ${ }^{60}$

Günümüzde Amerika'daki ulusal yeterlik standartları; Amerikan Diş Hekimliği Eğitimi Birliği (American Dental Education Association-ADEA ${ }^{43}$ tarafından 6 katagoride sınıflanmıştır. ADEA yeterlikleri; diş hekimliği fakültelerindeki müfredat değişiklikleri ve yenilikleri için rehber niteliğinde olup, akreditasyon standartlarını geliştirmede Amerikan Dental Akreditasyon Komisyonu'na (Comission on Dental Accreditation-CODA) yardımcı olur. Toplum destekli eğitim ADEA'nın yeterliklerinde söz edilmese de, yeterliklerdeki birçok madde öğrencilerin toplum destekli kliniklerde çalışması ve deneyim kazanmasıyla ilişkilendirilmektedir. ${ }^{63}$ Nebraska Üniversitesi'ndeki dördüncü sınıf öğrencileri; bir hafta mahalli muayenehanelerde, bir hafta süreyle kamu kliniklerinden birinde olmak üzere, toplam iki hafta rotasyona giderler. Rotasyon süresince öğrenciler; yönlendirici konumunda olan ve kamuda çalışan bir diş hekimi tarafından gözlemlenirler. Diş hekimi; öğrencilerin bu kurumlarda kapsamlı hasta tedavisi oluşturmalarını destekler ve rehberlik eder. Öğrenciler kimi zaman çocuk, kimi zaman yetişkin olmak üzere, herhangi bir beceri ayrımı olmadan, hastaların ihtiyacı olan tedavileri yaparlar. Yönlendirici; hastanın ihtiyacı ve öğrenci öğrenimi açısından en iyi tedaviyi belirler ve tedavi sürecini izler ve çoğunlukla aynı fakültenin mezunudur. Öğrenciler rotasyon yapacakları kurumlar ve yönlendiricileri için tercih yapabilirler. 2011-2012'de öğrenciler rotasyonlarını ülke çapındaki 38 kurumda tamamlamışlardır. Yönlendiriciler öğrencilerin rotasyondaki ADEA yeterliklerini değerlendirmişler; sağlığın iyileştirilmesi, hasta tedavisi ve profesyonellikte en yüksek başarı elde edilirken, muayenehane yönetimi, kritik düşünme ve iletişimde daha az yeterlik kazanmışlardır. ${ }^{63}$

Toplum destekli eğitime yeterliğe dayalı bir sistem ilave edilmesi; oğrencilerin önemli geri bildirim üretmelerine ve spesifik becerilerin gelişimi ve iyileştirilmesine odaklanmalarına neden olmuştur. ${ }^{56} \mathrm{Bu}$ nedenle gelecekte toplum destekli eğitim; öğrencilerin kendi kendilerini değerlendirebilmeleri ve hayat boyu öğrenme becerilerinde daha istekli olmalarını sağlayacaktır.

Geleneksel klinik eğitim modeli; belirli sayıda uygulama yapılması esasına dayanır ve öğrenciler mezuniyetteki yeterliklerinin değerlendirilmesinde bu uygulamaları ve kriterleri her anabilim dalı için yerine getirirler. Anabilim dallarına ait kriterler yerine getirilirken, öğrenciler arasında motivasyon sağlamak kolay olmamakla birlikte, mezuniyet sonrasındaki bağımsız çalışmalarına da sınırlı şekilde katkıda bulunur. ${ }^{64}$ 
Vaka tamamlama esasına dayanan klinik eğitim modeli; 2009'da Harvard School of Dental Medicine'da uygulanmış ve eğitimde öğrencilerin ihtiyaçlarını karşılamak yerine, hasta-merkezli kapsamlı tedavi kullanılmıştır. ${ }^{65,66}$ Bu modelde Park ${ }^{64 \prime} ı n$ vaka sınıflama sistemi esas alınır ve öğrencilerin tamamlayacakları vakalar 6 tipe ayrılır:

Tip 1. Koruyucu tedaviler, basit operatif uygulamalar, profilaksiler ile detertraj ve küretaj işlemleri

Tip 2. Multidisipliner yaklaşım (endodonti, peridontal cerrahi, ağız cerrahisi vs) ve protetik tedaviyi içermeyen kompleks restoratif uygulamalar

Tip 3. Multidisipliner yaklaşım ve protetik tedavileri (üç veya daha az üniteli sabit protezler) içeren restoratif uygulamalar

Tip 4. Kompleks multidisipliner yaklaşım (dört veya daha fazla anabilim dalı) ve protetik tedavileri (üç veya daha fazla üniteli sabit protezler) içeren veya zor klinik vakalar

Tip 5. Hareketli bölümlü protezler (metal ve rezin)

Tip 6. Tam protezler, immediat protezler, overdenture'lar ve implant-destekli overdenture'lar

Vaka tamamlama esasına dayanan klinik eğitim modelinde; öğrenciler mezuniyete kadar belirli sayıda ve sınıfa ait vaka tamamlarlar; bu eğitim modelinin hastaların tedavi koşullarını ve öğrencilerin öğrenimini iyileştirdiği bildirilmiştir. ${ }^{64}$

Uygulama becerilerinin direkt gözlenmesi (direct observation of procedural skills-DOPS) ve düzeltici geri bildirim (corrective feedback) klinik beceri eğitimini iyileştirmenin en önemli araçlarındandır. ${ }^{67} \mathrm{Bu}$ gözlem; periodontoloji ana bilim dalında klinik eğitim gören 15 lisans öğrencisine 4 fakülte öğretim üyesi tarafından uygulanmış; öğrencilerin ağız muayenesi, veri toplanması, periodontal değerlendirme, oral hijyen eğitimi, detertraj ve ultrasonik detertraj becerileri değerlendirilmiştir. Öğrenciler bu uygulamayı memnuniyetle karşılamış; öğrenim becerilerinin iyileşmesine yardımcı olduğunu ifade etmiş ve klinik eğitimlerinin başından itibaren, diğer klinik branşlara da uygulanmasını talep etmişlerdir. ${ }^{67}$

Yeterlik ve becerilerin değerlendirilmesini içeren klinik puanlamalar ve değerlendirmeler; öğrencilerin hünerlerini değerlendirmek için kullanılabilir ve genellikle öğrencileri hastalarla iletişimleri ve klinik performanslarına göre değerlendiren klinik eğitmenlerin varlığında yapılır. ${ }^{43}$ Günlük puanlamalar (daily clinical grades); eğitmen gözetiminde öğrencinin yaptığı uygulamanın her aşaması için değerlendirilmesidir. Klinik değerlendirmelerde (graded assessments) ise öğrenci klinik gözetmenin yardımı olmaksızın çalışır ve klinik uygulamanın her aşamasında değerlendirilir. Hem günlük puanlama hem de klinik değerlendirmede öğrencinin eleştirel düşünme, profesyonellik, iletişim, kişilerarası beceriler, sağlığın iyileştirilmesi, uygulama yönetimi gibi uyum becerileri ve hasta tedavilerindeki klinik becerileri için numerik puanlar kullanıılır. ${ }^{43}$

Diş hekimliği eğitimini çok yönlü olarak ele alan bir çalışmada ${ }^{68}$ eğitimde son durum şu şekilde özetlenmiştir: (1) Fakülteler devlet desteklerindeki kısıtlamalar, fakülte kliniklerinin masraflarını karşılama konusundaki yetersizlikleri nedeniyle ağır stres altındadır. (2) Eğitim sistemi diş hekimlerinin ulusal intiyaçlarını dikkate almadan genleşmektedir. (3)Müfredatlar aşırı yüklüdür; bilim ve teknolojideki ilerlemeler ile değişen uygulama yöntemleriyle uyum sağlamayı gerektirmektedir. Mezunlar; çocuk ve özel bakıma intiyaç duyan hastaları tedavi edebilecek seviyede değildirler. (4) Fakültelerdeki öğrenci sayısı artmasına rağmen, temel bilim eğitimi veren hocalar neredeyse \% 50 oranında azalmıştır. Bu durum muhtemelen fakültelerin masraf azaltma çabalarıyla ortaya çıkmıştır; ancak 
fakültelerdeki eğitimin ve araştırma programlarının kalitesinde azalmayla sonuçlanabilir. (5)Fakülte klinikleri güvenli eğitim üreticileri olmalarına karşın, bu son derece önemli görevleri karşılı̆ında yeterli maaş alamamaktadır. (6) Mezunlar muayenehane kliniklerinde çalışmak üzere yeterli değildirler; bunun yerine kendilerini kliniklerin bir partneri olarak çalışmak veya mezuniyet sonrası eğitimlerine devam etmek zorunda hissederler. Uzmanlık alanları; uygulamalı tedavilerin koşulları yerine hastalıkların tedavisine dayanacak şekilde yeniden düzenlenmelidir. Önümüzdeki on senede, fakülte öğretim görevlilerinin emekliye ayrılması kalifiye tam zamanlı eğitmenlerin eksikliğine yol açacaktır.

\section{SONUÇ}

Klinik eğitim sürecinde mesleki becerilere ilaveten kavramsal olmayan ve 21. yüzyıl uyum becerilerinin öğrencilere kazandırılması, eğitim kurumlarını kalitede daha ileriye taşır. Fakülte klinikleri öğrenciler için eğitim verme konusunda yetersizdir. Yetersiz klinik ve hastaya sahip fakültelerin, toplum destekli klinik eğitim modelini müfredatlarına taşımaları; mezun yeterliklerini iyileştirecektir.

Çoğu fakültenin klinik eğitim modeli; tedavi kalemlerinin işlem basamaklarının teknik yönü üzerinde odaklanırken, teşhis, tedavi planlaması ve hasta tedavisinin sonuçlarını anlamaktan uzaktır. Özellikle son sınıf öğrencileri için geleneksel klinik eğitim modelinde ısrar etmeyip, vaka tamamlama esasına dayanan klinik eğitim modeline geçmek, mezunların yeterliğe ulaşmasında daha faydalı olacaktır. Uygulama becerilerinde; fiziki koşullar ve insan kaynakları el verdiği ölçüde izlemeye dayalı değerlendirme yöntemlerinin dikkate alınması ve eğitmenlerin düzeltici geri bildirim üzerinde durması gerekir.

Preklinik eğitimde; öğrencilerin hasta tedavisi için gerçek durumları simüle eden ve daha çok klinikte karşılaşacakları beceriler için simülasyon eğitimi almaları faydalı olacaktır. Preklinik eğitimin zengin bilgisayar destekli ve sanal gerçeklik araçlarıyla desteklenmesi; sadece restoratif işlemler değil, enfeksiyondan korunma ve iletişim becerilerinin sanal hasta uygulamalarını da içermesi çağdaş diş hekimliği eğitiminin bir gereğidir. Standardize hastalar; hasta ile iletişim becerileri, muayene ve tedavi planlaması için düşünülmelidir.

Öğrencinin mesleki ve uyum becerilerinde yeterliğe ulaşmasını sağlamak; başarıı olamadığı durumlarda eğitim yöntemini geliştirmek; daha çok uygulama yapmasına fırsat vermek; öğrenmeye istekli hale gelmesini sağlamak ve eğitim paydaşları arasında sağlıkı iletişim ortamını oluşturmak eğitmenin ve fakülte idarecilerinin sorumluluğundadır. 


\section{KAYNAKLAR}

1. Perry S, Burrow MF, Leung WK, Bridges SM. Simulation and curriculum design: a global survey in dental education. Aust Dent J 2017; 62: 453-63.

2. Bridges S, Yiu CK, Botelho MG. Design considerations for an integrated, problem-based curriculum. Med Sci Educ 2016; 26: 365-73.

3. Lu J, Bridges SM, Hmelo-Silver CE. Problem-based learning. Sawyer K, ed. Cambridge Handbook of Learning Sciences Vol. 2. Netherlands: Cambridge University Press, 2014.

4. Manogue M, McLoughlin J, Christersson C, et al. Curriculum structure, content, learning and assessment in European undergraduate dental education-update 2010. Eur J Dent Educ 2011; 15: 133-41.

5. Haden NK, Hendricson WD, Kassebaum DK, Ranney RR, Weinstein G, Anderson EL. Curriculum change in dental education, 2003-09. J Dent Educ 2010; 74: 539-57.

6. Shuler CF. Dental school: balancing education and training. J Dent Educ 2014; 78: 655-6.

7. American Dental Education Association. Competencies for the New General Dentist. J Dent Ed 2011; 75: 9325.

8. Albino JE, Young SK, Neumann LM, Kramer GA, Andrieu SC, Henson L. Assessing dental students' competence: best practice recommendations in the performance assessment literature and investigation of current practices in predoctoral dental education. J Dent Educ 2008; 72: 1405-35.

9. Bertoli E, Lawson KP, Bishop SS. Dental Students' Skills Assessments: Comparisons of Daily Clinical Grades and Clinical and Laboratory Assessments. J Dent Educ 2018; 82: 417-23.

10. Gonzalez MAG, Abu Kasim NH, Naimie Z. Soft skills and dental education. European J Dent Educ 2013; 17: 7382.

11. Farmer R. Humanistic education and self-actualization theory. Education.105:162-72.

12. Schunk, D. H. Learning theories: An educational perspective. New York, NY, England: Macmillan Publishing Co, Inc., 2012.

13. Özvarış ŞB. Hacettepe Halk Sağlığı Vakfı Yayınları, Eğitim Becerileri Rehberi, 1999.

14. Licari FW, Evans CA. Clinical and Community-Based Education in U.S. Dental Schools J Dent Education. 2017; 81: 81-7.

15. Cederberg RA, Bentley DA, Halpin R, Valenza JA. Use of virtual patients in dental education: a survey of U.S. and Canadian dental schools, J Densoft Educ 2012;76: 1358-64.

16. Park SE, Tsao A. The Role of Online Learning in Radiographic Diagnosis in Dental Education. J Educ and Training Studies 2016; 4: 189-93. 
17. Field J, Stone S, Orsini C, Hussain A, Vital S, Crothers A, Walmsley D. Curriculum content and assessment of pre-clinical dental skills: A survey of undergraduate dental education in Europe. Eur J Dent Educ 2018; 22: 1227.

18. Eaton C. "I don't get it", - the challenge of teaching reflective practice to health and care practitioners. Reflective Pract. 2016; 17: 159-66.

19. Thilakumara IP, Jayasinghe RM, Rasnayaka SK, Jayasinghe VP, Abeysundara S. Effectiveness of Procedural Video Versus Live Demonstrations in Teaching Laboratory Techniques to Dental Students J Dent Educ 2018; 82: 898-904.

20. Scalese RJ, Obeso VT, Issenberg SB. Simulation technology for skills training and competency assessment in medical education. J Gen Intern Med 2008: 23: 46-9.

21. Al-Saud LM, Mushtaq F, Allsop MJ, Culmer PC, Mirghani I, Yates E et al. Feedback and motor skill acquisition using a haptic dental simulator. Eur J Dent Educ 2017; 21: 240-7.

22. Quinn F, Keogh P, McDonald A, Hussey D. A pilot study comparing the effectiveness of conventional training and virtual reality simulation in the skills acquisition of junior dental students. Eur J Dent Educ 2003; 7: 164-9.

23. Pohlenz P, Grobe A, Petersik A, Sterngerg N, Pflesser B, Pommert A. Virtual dental surgery as a new educational tool in dental school. J Craniomaxillofac Surg 2010; 38: 560-4.

24. Shumway-Cook A, Woollacott MH. Motor control: translating research into clinical practice. 4th edn. Philadelphia: Wolters Kluwer Health/Lippincott Williams \& Wilkins, 2012.

25. Feil PH, Reed T, Hart JK. Continuous knowledge of results and psychomotor skill acquisition. J Dent Educ 1986: 50: 300-3.

26. Wulf $\mathrm{G}$, Shea $\mathrm{CH}$. Principles derived from the study of simple skills do not generalize to complex skill learning. Psychon Bull Rev 2002: 9: 185-211.

27. Huegel JC, O'Malley MK. Progressive haptic and visual guidance for training in a virtual dynamic task. In: Proceedings IEEE Haptics Symp 2010; (April): 343-50.

28. Strom P, Hedman L, Sarna L, Kjellin A, Wredmark T, Fellander-Tsai L. Early exposure to haptic feedback enhances performance in surgical simulator training: a prospective randomized crossover study in surgical residents. Surg Endosc 2006; 20: 1383-8.

29. Bethea BT, Okamura AM, Kitagawa M, Fitton TP, Cattaneo SM, Gott VL. Application of haptic feedback to robotic surgery. J Laparoendosc Adv Surg Tech A 2004; 14: 191-5.

30. Panait L, Akkary E, Bell RL, Roberts KE, Dudrick SJ, Duffy AJ. The role of haptic feedback in laparoscopic simulation training. J Surg Res 2009; 156: 312-6.

31. Sewell C, Peddamatham S, Tan HZ, Tan Hz, Morris D, Salisbury K. The effect of virtual training on real surgical drilling proficiency. EuroHaptics Conference and symposium on haptic interfaces for virtual environment and teleoperator systems, Tsukaba; 2007: 601-3. 
32. Buchanan JA. Use of simulation technology in dental education. J Dent Educ 2001: 65: 1225-31.

33. Nilsson TA, Hedman R, Ahlqvist JB. A randomized trial of simulationbased versus conventional training of dental student skill at interpreting spatial information in radiographs. Simul Heal 2007: 2: 164-9.

34. Wierinck E, Puttemans V, Swinnen S, van Steenberghe D. Effect of augmented visual feedback from a virtual reality simulation system on manual dexterity training. Eur J Dent Educ 2005: 9: 10-6.

35. Gratton DG, Kwon SR, Blanchette D, Aquilino SA. Impact of Digital Tooth Preparation Evaluation Technology on Preclinical Dental Students' Technical and Self-Evaluation Skills. J Dent Educ 2016; 80(1): 91-9.

36. Guenzel PJ, Knight GW, Feil PH. Designing preclinical instruction of psychomotor skills (IV)-instructional engineering: evaluation phase. J Dent Educ 1995;59(4): 489-94.

37. Johnson GM, Halket CA, Ferguson GP, Perry J. Using Standardized Patients to Teach Complete Denture Procedures in Second Year of Dental School J Dent Educ 2017; 81(3): 340-6.

38. McKenzie CT, Tilashalski KR, Peterson DT, White ML. Effectiveness of standardized patient simulations in teaching clinical communication skills to dental students. J Dent Educ 2017; 81(10): 1179-86.

39. Anders PL, Scherer YK, Hatton M, Antonson D, Austin-Ketch T, Campbell-Heider N. Using Standardized Patients to Teach Interprofessional Competencies to Dental Students. J Dent Educ 2016; 80(1): 65-72.

40. Brender E, Burke A, Glass RM. Standardized patients. JAMA 2005; 294(9): 1172.

41. Walsh SE, Singleton JA, Worth CT, Krugler J, Moore R, Wesley G.Tobacco cessation counseling training with standardized patients. J Dent Educ 2007; 71(9): 1171-8.

42. Broder HL, Janal M, Mitnick DM, Rodriquez JY, Sischo L. Communication skills in dental students: new data regarding retention and generalization of training effects. J Dent Educ 2015; 79: 940-8.

43. American Dental Education Association. ADEA competencies for the new general dentist. J Dent Educ 2017; 81: 844-7 (p 844).

44. Hendricson W, Anderson E, Andrieu S, Chadwick DG, Cole JR, George MC. Does faculty development enhance teaching effectiveness? J Dent Educ 2007; 71: 1513-33.

45. Victoroff KZ, Hogan S. Students' perceptions of effective learning experiences in dental schools: a qualitative study using a critical incident technique. J Dent Educ 2006; 70: 124-32.

46. Graffam B. Deriving better questions: creating better clinical instruction. Clin Teach. 2008; 5: 98-102.

47. Collins A., Brown JS, Newman SE. Cognitive apprenticeship: teaching the crafts of reading, writing, and mathematics. In: Resnick LB ed. Knowing, Learning, and Instruction: Essays in Honor of Robert Glaser. Hillsdale, New Jersey: Lawrence Erlbaum Associates, Inc; 1989: 453-94.

48. Stalmeijer RE, Dolmans DHJM, Wolfhagen IHAP, Muijtjens AMM, Scherpbier AJJA. The development of an instrument for evaluating clinical teachers: involving stakeholders to determine content validity. Med Teach. 2008; 30: 272-7. 
49. Rutkauskas J, Seale S, Casamassimo P, Rutkauskas JS. Preparedness of entering pediatric dentistry residents: advanced pediatric program directors' and first-year residents' perspectives. J Dent Educ 2015; 79: 1265-71.

50. Holmes DC, Boston DW, Budenz AW, Licari FW. Predoctoral clinical curriculum models at U.S. and Canadian dental schools. J Dent Educ 2003; 67: 1302-11.

51. Makarem SC, Coe JM. Patient retention at dental school clinics: a marketing perspective. J Dent Educ 2014; 78: 1513-20.

52. Formicola AJ, Bailit HL. Community-based dental education: history, current status, and future. J Dent Educ 2012; 76: 98-106.

53. Formicola AJ, Myers R, Hasler JF, Peterson M, Dodge W, Bailit HL. Evolution of dental school clinics as patient care delivery centers. J Dent Educ 2006; 70: 1271-88.

54. DePaola DP. The revitalization of U.S. dental education. J Dent Educ 2008; 72: 28-42.

55. Cohen DW, Cormier PP, JL. Educating the dentist of the future: the Pennsylvania experiment. Philadelphia: University of Pennsylvania Press, 1985.

56. McFarland KK, Nayar P, Ojha D, Chandak A, Gupta N, Lange B. Impact of Community-Based Dental Education on Attainment of ADEA Competencies: Students' Self-Ratings. J Dent Educ 2016; 80: 670-6.

57. Commission on Dental Accreditation. Accreditation standards for dental education programs. 2013. At: www.ada.org/ /media/CODA/Files/predoc.ashx. Accessed 15 July 2015.

58. DeCastro JE, Matheson PB, Panagakos FS, Stewart Dci Feldman CA. Alumni perspectives on community-based and traditional curricula. J Dent Educ 2003; 67: 418-26.

59. Bean CY. Community-based dental education at The Ohio State University: the OHIO project. J Dent Educ 2011; 75: 25-35.

60. Mascarenhas AK. Community-based dental education at Boston University. J Dent Educ 2011; 75: 21-4.

61. Piskorowski WA, Stenafac SJ, Fitzgerald M, Green TG, Krell RE. Influence of community-based dental education on dental students' preparation and intent to treat underserved populations. J Dent Educ 2012; 76: 534-9.

62. Knight GW. Community-based dental education at the University of Illinois at Chicago. J Dent Educ 2011; 75: 14-20.

63. Nayar P, McFarland K, Lange B, Ojha D, Chandak A. Supervising dentists' perspectives on the effectiveness of communitybased dental education. J Dent Educ 2014; 78: 1139-4

64. Park SE, Howell TH. Implementation of a Patient-Centered Approach to Clinical Dental Education: A Five-Year Reflection. J Dent Educ 2015; 79: 523-9.

65. Park SE, Timothe $\mathrm{P}$, Nalliah $\mathrm{R}$, et al. A case completion curriculum for clinical dental education: replacing numerical requirements with patient-based comprehensive care. J Dent Educ 2011; 75: 1411-6. 
66. Park SE, Susarla HK, Nalliah R, Timothe P, Howell TH, Karimbux NY. Does a case completion curriculum influence dental students' clinical productivity? J Dent Educ 2012; 76: 602-8.

67. Singh G, Kaur R, Mahajan A, Thomas AM, Singh T. Piloting Direct Observation of Procedural Skills in Dental Education in India. Int J Appl Basic Med Res 2017; 7(4): 239-42.

68. Formicola AJ. Current state of dental education: Executive summary J Dent Educ 2017; 81(8): 1.

Yazışma Adresi:

Prof. Dr. Funda AKALTAN

Ankara Üniversitesi Diş Hekimliği Fakültesi

Protetik Diş Tedavisi Anabilim Dalı

Beşevler 06560, Ankara

E-posta : akaltanfunda@gmail.com 